\title{
TREE CANOPY HEIGHT ESTIMATION USING MULTI BASELINE RVOG INVERSION TECHNIQUE
}

\author{
Arun Babu ${ }^{1, *}$, Shashi Kumar ${ }^{1}$ \\ ${ }^{1}$ Photogrammetry and Remote Sensing Department, Indian Institute of Remote Sensing, Uttrakhand, India - \\ arunlekshmi1994@gmail.com, shashi@iirs.gov.in
}

Commission V, SS: Emerging Trends in Remote Sensing

KEYWORDS: PolInSAR, Tree Canopy Height, Random Volume over Ground, UAVSAR, AfriSAR, coherence

\begin{abstract}
:
Polarimetric Interferometric Synthetic Aperture Radar (PolInSAR) technique utilizes the characteristics of both SAR polarimetry and Interferometry. PolInSAR technique is proved to be very useful for vegetation parameters retrieval. Estimation of the tree canopy height parameter is very important for the estimation of the Above Ground Biomass (AGB). The baseline separation between different PolInSAR datasets has a very important role in the tree canopy height estimation due to the sensitivity of the baseline to the tree height and the forest structure. So for accurately estimating the tree canopy height of a forest with varying tree heights and species several pairs of PolInSAR datasets with different baselines separations are required. Multi-baseline Random Volume over Ground (RVoG) inversion technique is the most successful method for tree height inversion. UAVSAR, the Quad-Pol L-band airborne SAR of JPL/NASA acquired PolInSAR datasets over the Gabon forest as a part of the AfriSAR campaign. Nine PolInSAR SLC datasets of this campaign acquired over the Mondah Forest site of Gabon forest is used for this study. Tree canopy height map produced from this datasets shows that the tree height is varying at this site and has a maximum height of $50 \mathrm{~m}$. The results obtained are validated using the field data collected by JPL/NASA during March 2016. The comparison of the results with the field data showed that both are in good agreement with an average deviation of $3.75 \mathrm{~m}$.
\end{abstract}

\section{INTRODUCTION}

Forests play an important role in Earth's carbon cycle by absorbing carbon from the atmosphere and storing it in the form of above ground biomass. Tree canopy height is a very important parameter required for the estimation of aboveground biomass (Mohd Zaki et al., 2018). Remote sensing techniques are capable of estimating tree canopy height quickly in a regional as well as global scale without the requirement of rigorous fieldwork. Synthetic Aperture Radar (SAR) techniques are preferred for this purpose because of its all-weather, all-time operational capability and also because of its capability of L-band and P-band to penetrate the forest canopy.

SAR Polarimetry, Polarimetric SAR Interferometry (PolInSAR) and SAR tomography have shown its potential for tree canopy height estimation. SAR polarimetry uses various scattering models to analyse the forest structure and to retrieve the forest parameters (Sai Bharadwaj et al., 2015). SAR tomography is a still-emerging technique which is capable of estimating the 3Dvertical profile of the forest structure (Kumar et al., 2017a). PolInSAR uses a coherent combination of interferograms in different polarizations. The interferograms help to estimate the spatial diversity of the forest vertical structure and hence the accurate measurement of the scattering centres. While the different polarizations available, which are sensitive to shape, dielectric property and orientation of the scattering elements help to identify the scattering mechanisms in a single resolution cell. PolInSAR technique uses various inversion models to estimate the forest parameters. Random Volume over Ground (RVoG) model is the most successful inversion model for the estimation of tree canopy height. This model utilizes the volume decorrelation for tree height retrieval(Kumar et al., 2017b). The inversion of RVoG model using single baseline PolInSAR data assumes that in at least one of the observed polarization channels (usually the cross-polarized HV channel), the effective ground to volume ratio is small. However, in some cases when vegetation is thick, dense, or the penetration of the electromagnetic wave is weak, the assumption fails (Zhou et al., 2009). The accurate forest height determination using PolInSAR requires an ideal baseline between the dataset pairs which is further dependent on the vertical structure of the forest, tree height and platform-target geometry. So no single baseline can accurately estimate the tree canopy height for both short and tall forest areas. RVoG inversion model using multi-baseline PolInSAR datasets can be used to mitigate this problem (Lee et al., 2011). Multi-baseline datasets for PolInSAR processing refers to the coregistered set of datasets acquired in different tracks with zero horizontal spatial baseline separation and with different vertical spatial baseline separation. The length of the vertical baselines between the tracks determines the sensitivity of the interferometric phase differences to the radar scatterers of different height. Shorter baselines are capable of estimating the height of taller trees while longer baselines are optimum for estimating the height of shorter trees. The PolInSAR technique requires interferometric pair Quad-Pol datasets with appropriate baselines.

The Uninhabited Aerial Vehicle Synthetic Aperture Radar (UAVSAR) is the airborne Quad-Pol SAR system developed by JPL/NASA. It operates in L-band in a frequency range from 1217.5 MHz to $1297.5 \mathrm{MHz}$ and employs an electronically scanned phased array radar. The radar is attached in a pod mounted to the fuselage of a Gulfstream III aircraft. UAVSAR nominally files at an altitude of $12.5 \mathrm{~km}$ and maps a $22 \mathrm{~km}$ swath with incidence angle varying from 25 degrees to 60 degrees. The primary design objective of the radar is to collect repeat-pass interferometric data. For achieving this purpose the electronic beam steering system of the SAR antenna is tied to the inertial navigation unit of the aircraft to maintain beam pointing accuracy regardless of the platform yaw. The UAVSAR platform was also

\footnotetext{
* Corresponding author
} 
modified to incorporate a precision autopilot system which allows the aircraft to fly within a $5 \mathrm{~m}$ tube. This empowers the UAVSAR to fly a progression of flight lines with fixed interferometric baselines. The UAVSAR SLC datasets have an azimuth spacing of $0.6 \mathrm{~m}$ and a range spacing of $1.6 \mathrm{~m}$ (Rosen et al., 2007).

The Congo Basin's tropical forests known as "the second lungs of the Earth", covering more than 198 million hectares are the second largest in the world after those of the Amazon Basin. The Gabon forest which is a part of this Congo Basin covers an area between 17 to 20 million hectares which is almost $80 \%$ of the entire country. Gabon's forests are huge carbon reservoirs sequestering 0.94 to 5.24 gigatons of carbon. suitable for multi-baseline RVoG model studies because of the presence of short mangroves and very tall Mahogany trees providing large diversity in tree heights. The data is acquired on $6^{\text {th }}$ March 2016 in 9 tracks producing 9 sets of Quad-Pol datasets with nearly zero horizontal baseline separation and different vertical baselines (Table 1).

\subsection{Methods}

2.2.1 Methodology for Tree canopy height estimation: The flowchart of the methodology is shown in (Figure 2). Initially 12:5 multilooking is done to the UAVSAR SLC datasets having an azimuth spacing of $0.6 \mathrm{~m}$ and a range spacing of $1.6 \mathrm{~m}$ to produce the MLC datasets with an azimuth spacing of $12 \mathrm{~m}$ and range spacing of $8 \mathrm{~m}$.

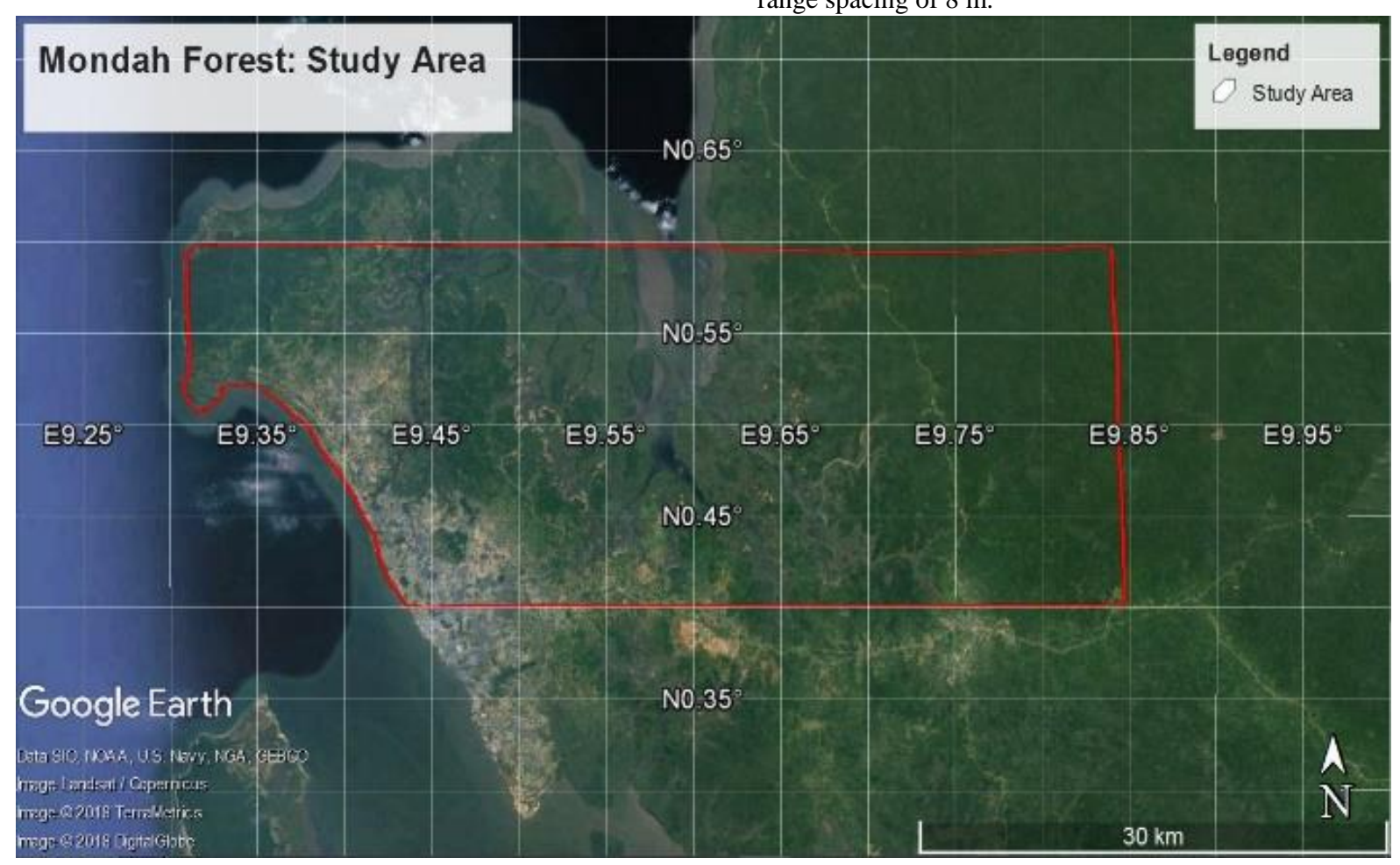

Figure 1. Study Area

In 2015 NASA and ESA entered into a joint programme called the "AfriSAR campaign" to collect airborne synthetic aperture radar data, LiDAR data and field data. The primary objective of the campaign was to collect accurate data for the calibration and validation purposes of the upcoming spaceborne satellites for studying the role of forests in the Earth's carbon cycle. As a part of this campaign, JPL /NASA's UAVSAR acquired airborne SAR data at different test sites of Gabon forest in March 2016. Field data is also collected at selected plots in this test site during the same month.

In this paper, the tree canopy height estimation using UAVSAR Quad-Pol L-band PolInSAR datasets acquired as part of AfriSAR campaign and the multi-baseline RVOG inversion technique is discussed.

\section{DATASETS AND METHODS}

\subsection{Datasets}

The datasets used for this study is the UAVSAR Quad-Pol PolInSAR datasets acquired over the Mondah forest area test site of the Gabon forest (Figure 1). Mondah forest area is very
The MLC datasets are then converted to Pauli basis scattering vector $(\vec{k})$ by assuming scattering reciprocity (Cloude et al., 2001, 1998; Denbina et al., 2018; Kumar et al., 2017b; Lee et al., 2009)

\begin{tabular}{|c|c|c|}
\hline $\begin{array}{c}\text { Track } \\
\text { No }\end{array}$ & $\begin{array}{c}\text { Date of } \\
\text { Acquisition } \\
\text { (dd/mm/yyyy) }\end{array}$ & $\begin{array}{c}\text { Vertical } \\
\text { Baseline }(\mathrm{m})\end{array}$ \\
\hline 1 & $06 / 03 / 2016$ & Reference track \\
\hline 2 & $06 / 03 / 2016$ & 0 \\
\hline 3 & $06 / 03 / 2016$ & 0 \\
\hline 4 & $06 / 03 / 2016$ & 45 \\
\hline 5 & $06 / 03 / 2016$ & 45 \\
\hline 6 & $06 / 03 / 2016$ & 45 \\
\hline 7 & $06 / 03 / 2016$ & 60 \\
\hline 8 & $06 / 03 / 2016$ & 60 \\
\hline 9 & $06 / 03 / 2016$ & 60 \\
\hline
\end{tabular}

Table 1. Metadata of datasets

$$
\vec{k}=\frac{1}{2}\left[S_{H H}+S_{V V}, S_{H H}-S_{V V}, 2 S_{H V}\right]
$$


Equation (1) is calculated for all the pixels in the SLC datasets of 9 tracks. The scattering vector for a track ' $\mathrm{m}$ ' is represented as $\vec{k}_{m}$. The scattering vectors of all the 9 tracks are stacked together to form the multi-track scattering vector $\vec{K}$ represented below:

$$
\vec{K}=\left[\begin{array}{c}
\vec{k}_{1} \\
\vec{k}_{2} \\
\cdots \\
\ldots \\
\vec{k}_{9}
\end{array}\right]
$$

The covariance matrix for all the 9 tracks are computed as follows:

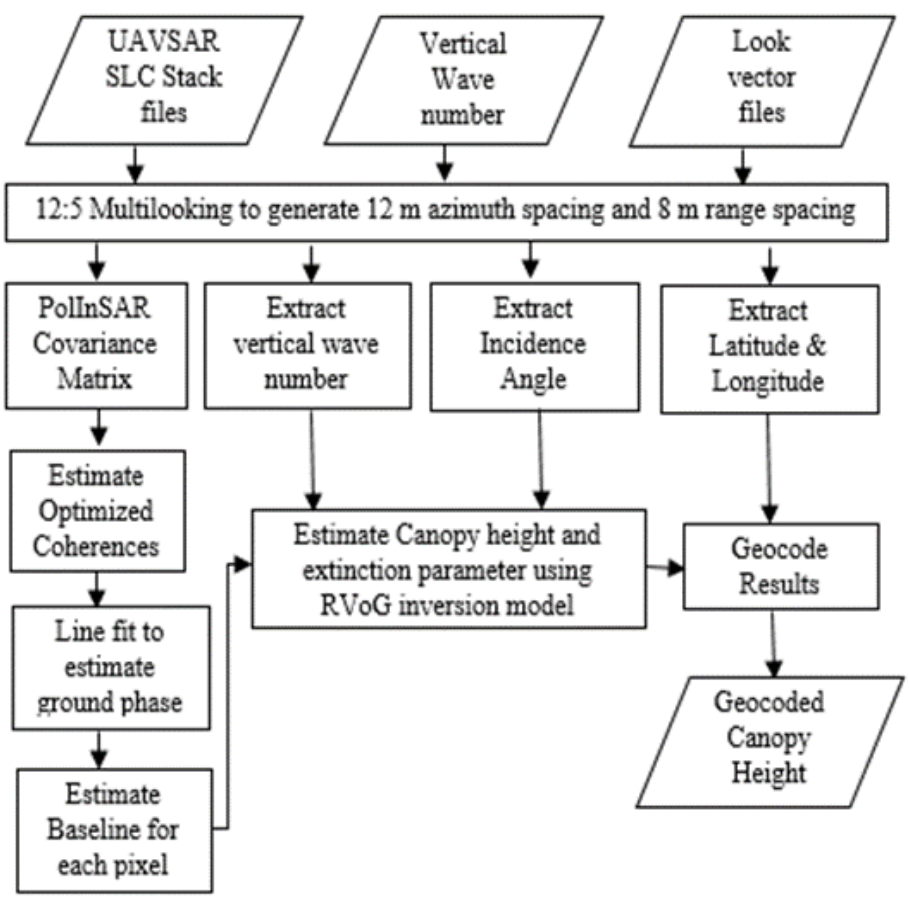

Figure 2. Flowchart of Methodology

$$
T=\left\langle\vec{K} \vec{K}^{H}\right\rangle
$$

Where ' $\mathrm{H}$ ' represents the Hermitian matrix. The matrix $\mathrm{T}$ for multi- baseline PolInSAR datasets is represented as follows (Denbina et al., 2018; Neumann et al., 2010):

$$
T_{M B}=\left[\begin{array}{cccc}
T_{1} & \Omega_{1,2} & \ldots & \Omega_{1, M} \\
\Omega_{1,2}^{H} & T_{2} & \ldots & \Omega_{2, M} \\
\ldots & \ldots & \ldots & \ldots \\
\Omega_{1,9}^{H} & \Omega_{2,9}^{H} & \ldots & T_{9}
\end{array}\right]
$$

The $T_{M} \& \Omega_{m, n}$ matrices are separate $3 \times 3$ matrices, where $T_{M}$ is the polarimetric covariance matrix $\& \& \Omega_{m, n}$ is the polarimetric $\&$ interferometric covariance matrix for the reference track ' $\mathrm{m}$ ' $\&$ secondary track ' $n$ '.

The complex coherence $\gamma$ for any desired baseline pair is estimated as follows (Cloude et al., 1998; Joshi et al., 2016; Kumar et al., 2018):

$$
\gamma=\frac{\vec{\omega}^{H} \Omega_{m, n} \vec{\omega}}{\sqrt{\left(\vec{\omega}^{H} T_{M} \vec{\omega}\right)\left(\vec{\omega}^{H} T_{n} \vec{\omega}\right)}}
$$

In equation (5), $\vec{\omega}$ is the complex polarimetric weight factor which weights the linear combinations of polarizations to use for computing the coherence.

The canopy- dominated coherence $\left(\gamma_{\text {high }}\right)$ and ground dominated $\left(\gamma_{\text {low }}\right)$ coherence are estimated by using a phase diversity coherence optimization technique which maximizes the value of $\left|\gamma_{\text {high }}-\gamma_{\text {low }}\right|$ (Denbina et al., 2018; Flynn et al., 2002).

For tree height estimation using multi-baseline RVoG inversion technique, dataset pairs with suitable baseline need to be selected for each pixel. This is by selecting baselines having the large separation between canopy dominated coherence and ground dominated coherence, high overall coherence and having strong phase diversity as a function of polarization. This is represented mathematically as follows (Denbina et al., 2018):

$$
\text { prod }=\left(\left|\gamma_{\text {high }}-\gamma_{\text {low }}\right|\right)\left(\left|\gamma_{\text {high }}+\gamma_{\text {low }}\right|\right)
$$

The baseline with the highest value of 'prod' is selected as the optimum baseline for each pixel.

The mathematical representation of $\mathrm{RVoG}$ inversion technique is as follows (Cloude et al., 2003; Treuhaft et al., 1996):

$$
\gamma_{r v o g}=e^{j \phi} \frac{\mu+\alpha_{v t} \gamma_{v}}{\mu+1}
$$

Where $\gamma_{r v o g}$ is the modelled complex coherence, $\phi$ is the interferometric phase of the ground, $\mu$ is the ground to volume scattering amplitude ratio, $\gamma_{v}$ is the volume coherence and $\alpha_{v t}$ is the temporal decorrelation factor. The volume coherence $\gamma_{v}$ is estimated using the following equations (Cloude et al., 2001, 2003; Kugler et al., 2015)

$$
\begin{gathered}
\gamma_{v}=\frac{p_{1}\left(e^{p_{2} h_{v}}-1\right)}{p_{2}\left(e^{p_{1} h_{v}}-1\right)} \\
p_{1}=\frac{2 \sigma_{x} \cos \tau_{c}}{\sin \left(\theta-\tau_{c}\right)} \\
p_{2}=p_{1}+j k_{z}
\end{gathered}
$$

Where $h_{v}$ is the forest canopy height, $\sigma_{x}$ is the extinction coefficient of microwaves within the forest canopy $(\mathrm{Np} / \mathrm{m}), k_{z}$ is the interferometric vertical wavenumber $(\mathrm{rd} / \mathrm{m})$ and $\tau_{c}$ is the slope angle of the underlying terrain.

The $k_{z}$ file provided by JPL/NASA is used for estimating the other parameters and the $\tau_{c}$ is assumed as zero.

The interferometric ground coherence $e^{j \phi}$ is estimated by using a line fit between the optimized coherences $\gamma_{\text {high }}$ and $\gamma_{\text {low }}$. The ground coherence is found at one of the intersections between the fitted line and the unit circle. Out of the two intersections with the unit circle the value which gives the height of the observed phase centre less than $\pi / k_{z}$ is taken as the ground coherence.

After estimating all the unknowns, the equation (7) is solved for estimating the tree canopy height $\left(h_{v}\right)$. 
2.2.2 Methodology for result validation using field data: The result obtained is validated using the field data collected by JPL/NASA during March 2016. The field data is collected by measuring the tree canopy heights at the 0.25 ha and 1 ha plots selected at the Mondah study area. Sixteen 0.25 hectare plots are used for validating the result obtained. Initially, shapefile of the plots are produced and overlaid with the raster height map. The pixels lying inside the plots are selected and 4 pixels in azimuth and 6 pixels in range direction are averaged together to produce a pixel size of $48 \mathrm{~m} \mathrm{x} 48 \mathrm{~m}$ which match closely with the $50 \mathrm{~m} \mathrm{x}$ $50 \mathrm{~m}$ plots on the ground.

JPL/NASA collected field data from Mondah forest area which covers the swath of the UAVSAR PolInSAR datasets during March 2016. The field data is collected by measuring the tree canopy heights at $0.25 \mathrm{ha}(50 \mathrm{~m} \times 50 \mathrm{~m})$ and 1 ha plots selected at the study area. The heights of the trees were measured at these plots and averaged to produce a single tree canopy height value for that particular plot.
Sixteen 0.25 ha plots are used for validating the results obtained. Initially, the shapefile of the plots are produced and overlaid with the raster height map. The pixels lying inside the plots are selected and 4 pixels in azimuth and 6 pixels in range direction are averaged together to produce a pixel size of $48 \mathrm{~m} \mathrm{x} 48 \mathrm{~m}$ which match closely with the $50 \mathrm{~m}$ x $50 \mathrm{~m}$ plots on the ground.

The estimated tree heights are then compared with the field data to validate the results.

\section{RESULTS AND DISCUSSIONS}

Multi-baseline RVoG inversion using the above-described methodology is performed and obtained the results which are discussed below:

The figure 3 shows the canopy dominated coherence image of the study area. Canopy dominated coherence indicates the volume scattering component from the tree structure. Estimating the canopy coherence is required to identify the scattering phase centres which gives information about the vertical depth of the
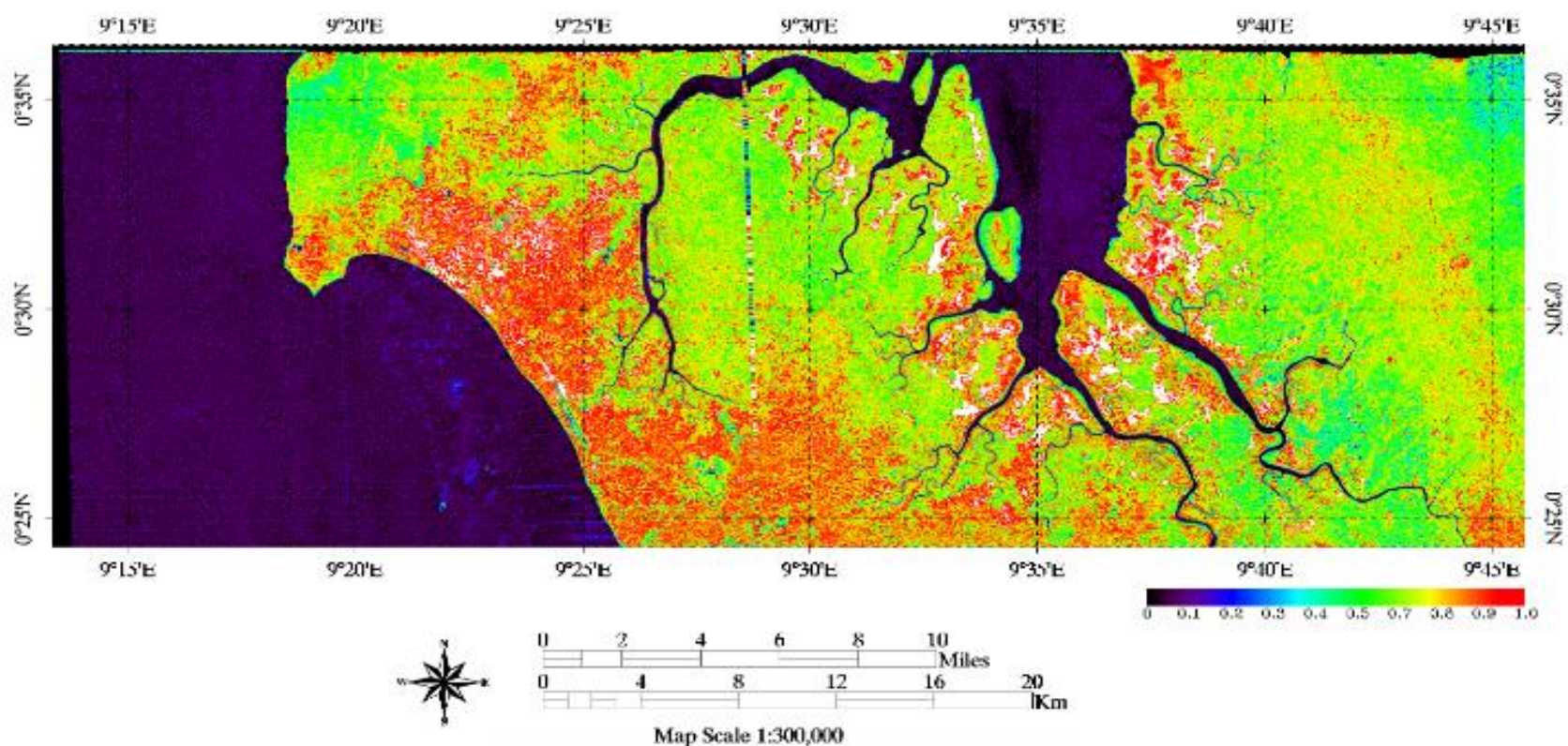

Figure 3. Canopy dominated coherence

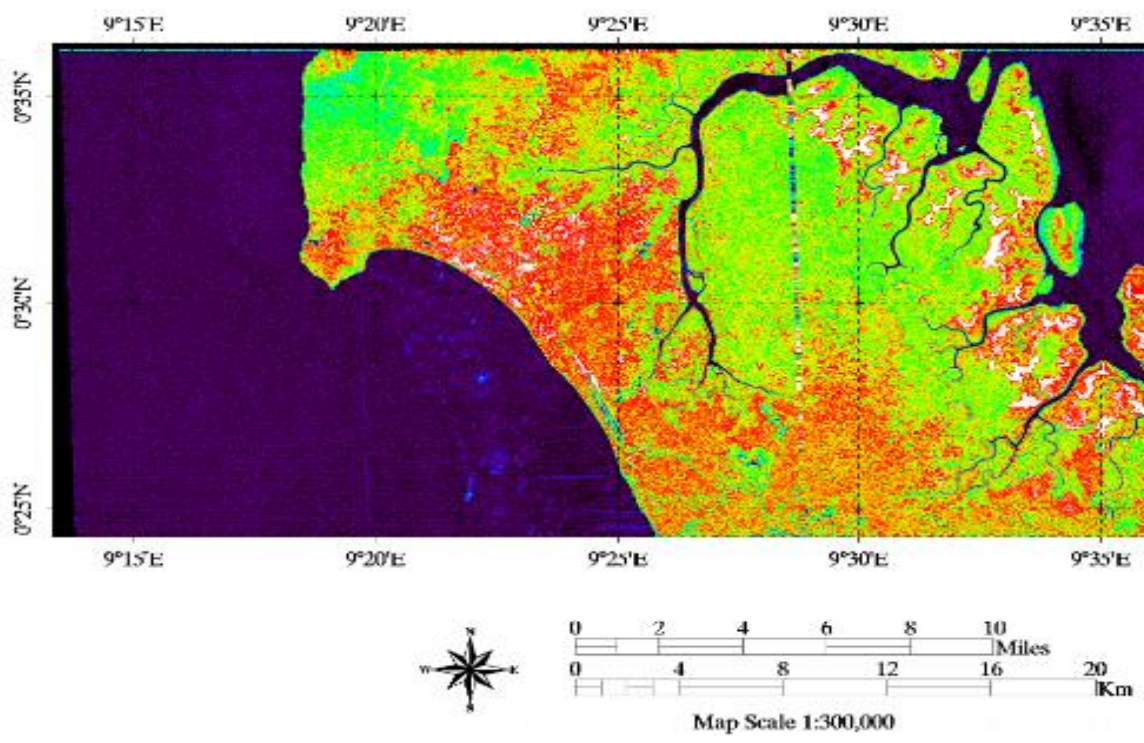

Figure 4. Ground dominated coherence 


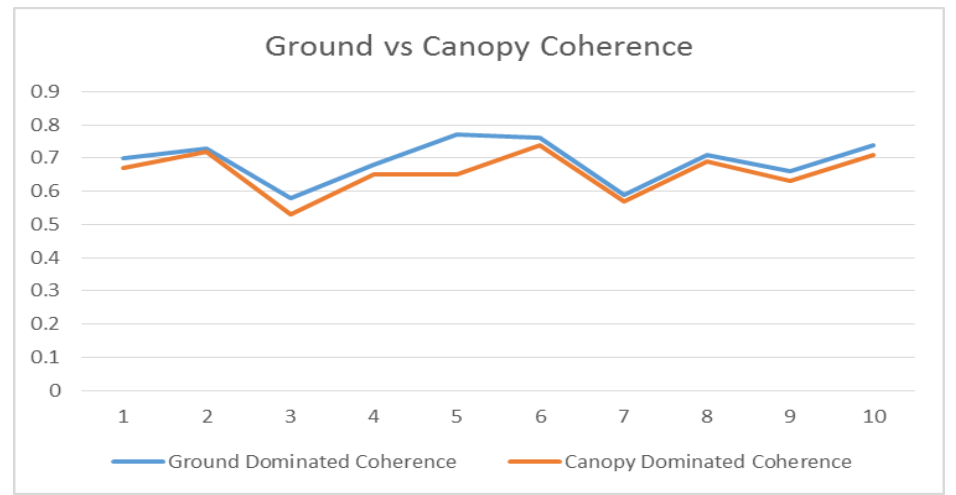

is slightly higher than the Canopy dominated coherences. It is due to the capability of the L-Band EM wave to penetrate more to the ground through the forest canopy and also due to the absence of volume decorrelation.

Both the canopy dominated coherence and ground dominated coherence are used for the coherence optimization procedure to identify the baseline pairs which offer maximum separation between these coherences and hence the respective scattering phase centres which are very important for accurate tree canopy height estimation.

Figure 5. Ground vs Canopy dominated coherence

forest. From the figure, it can be seen that the barren lands in the study area are having very high coherence greater than 0.8 shown in red colour. The vegetated areas are having medium coherence in the range 0.5 to 0.75 shown in green to the yellow colour range. The reduced value of canopy dominated coherence in the vegetated areas is due to the volume decorrelation introduced mainly due to the wind which alters the orientation of the leaves. Since the datasets are acquired on the same day other atmospheric effects are negligible. The blue regions are the water bodies having very low coherence.

The Ground dominated coherence of the study area is shown in figure 4 . Ground dominated coherence indicates the surface and double-bounce scattering components from the ground beneath the forest canopy. By comparing figure 3 and figure 4 it can be seen that both the canopy dominated coherence and ground dominated coherence are almost similar with an only a small difference in between. As seen in the canopy dominated coherence image, the barren lands are having the highest ground coherence of 0.8 and above in figure 4 also. The vegetated areas are having medium ground coherence from 0.5 to 0.78 .

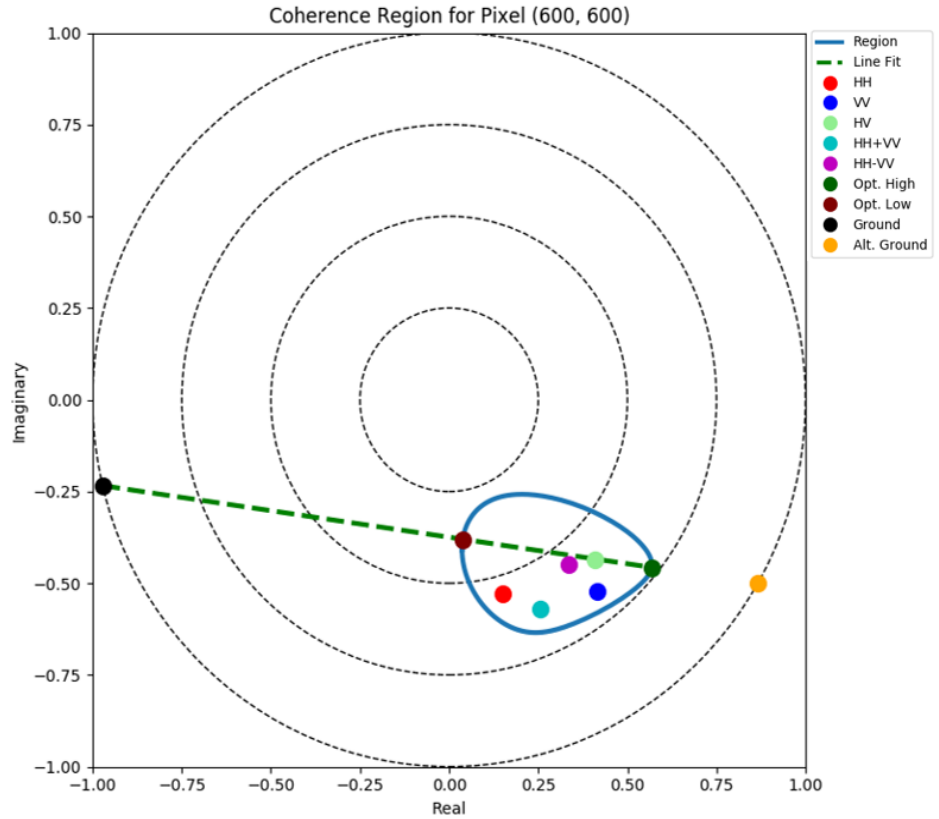

Figure 6. Coherence Region plot

From the figure 5 it can be seen that in vegetated areas where the thick forest is present the value of Ground dominated coherence

Figure 6 shows the coherence region plot of a single pixel. Inside the unit circle, the coherence region itself is shown as the solid

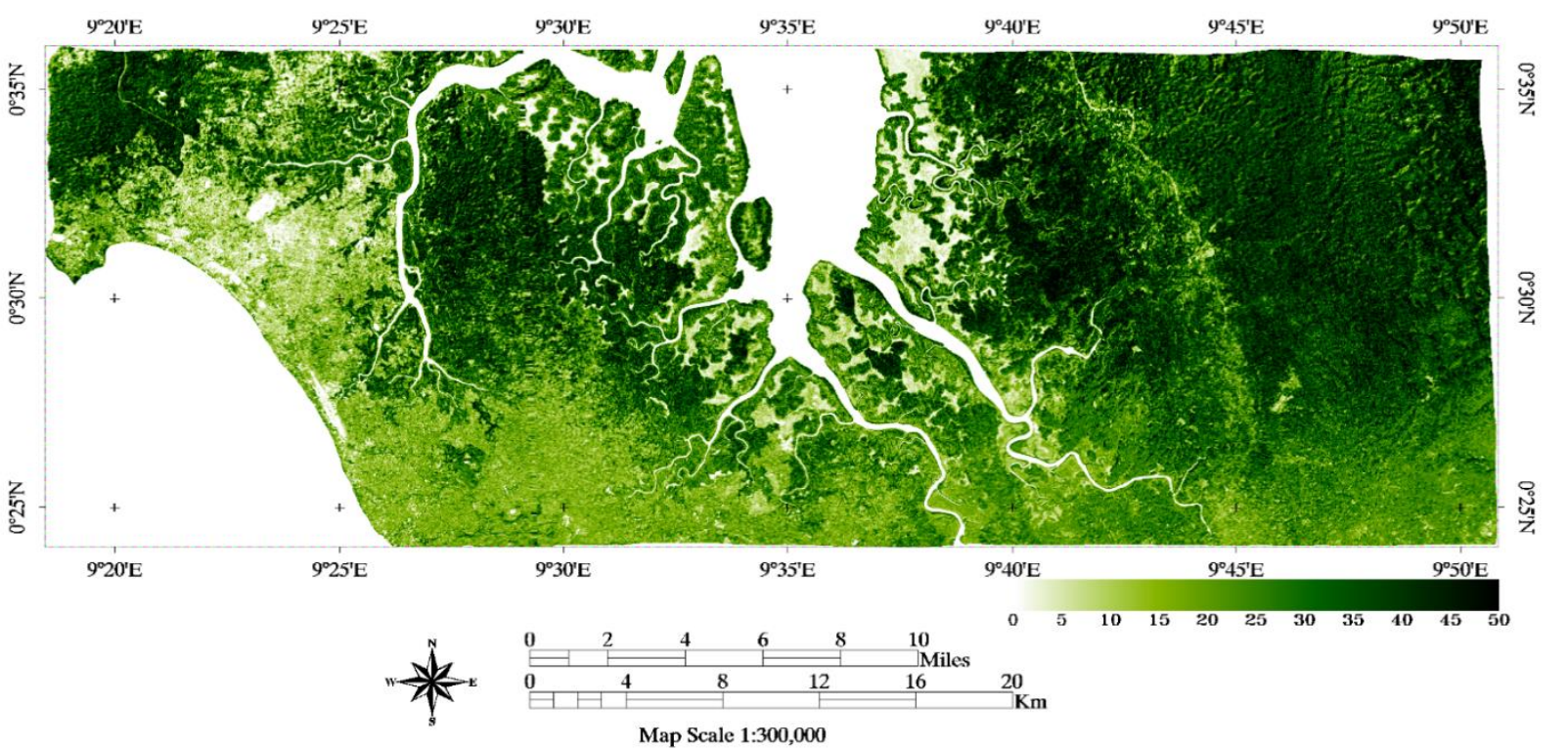

Figure 7. Tree Canopy height 
blue line. Each of the standard lexicographic and Pauli basis coherences is plotted as different coloured dots. The HV coherence is shown in light green. The complex coherences with maximum separation estimated through phase diversity optimization technique is shown by the dark green and brown dots located on the edge of the coherence region. The high coherence shown in dark green has the lowest ground contribution of any polarization in the data. The low coherence shown in brown has the highest ground contribution. The dashed green line is the line fitted to these optimized coherences. At the points where this line intersects the unit circle, there are two coherences plotted, one in black, and one in orange. The black dot is the ground coherence chosen by the algorithm as per the show the water bodies and barren lands which are masked out from the process and assigned with zero height values. The lighter shades of green indicate lower tree canopy height values and the darker shades of green indicates higher tree canopy height. The tree canopy height estimated reaches up to a maximum height of $50 \mathrm{~m}$.

Figure 8 shows the graph between the vertical wave number and tree canopy height. By analysing the graph it can be seen that the vertical wave number values are varying randomly with respect to different tree canopy height values and it is not possible to establish a relationship between the changes in vertical wave number values with respect to the tree canopy height.

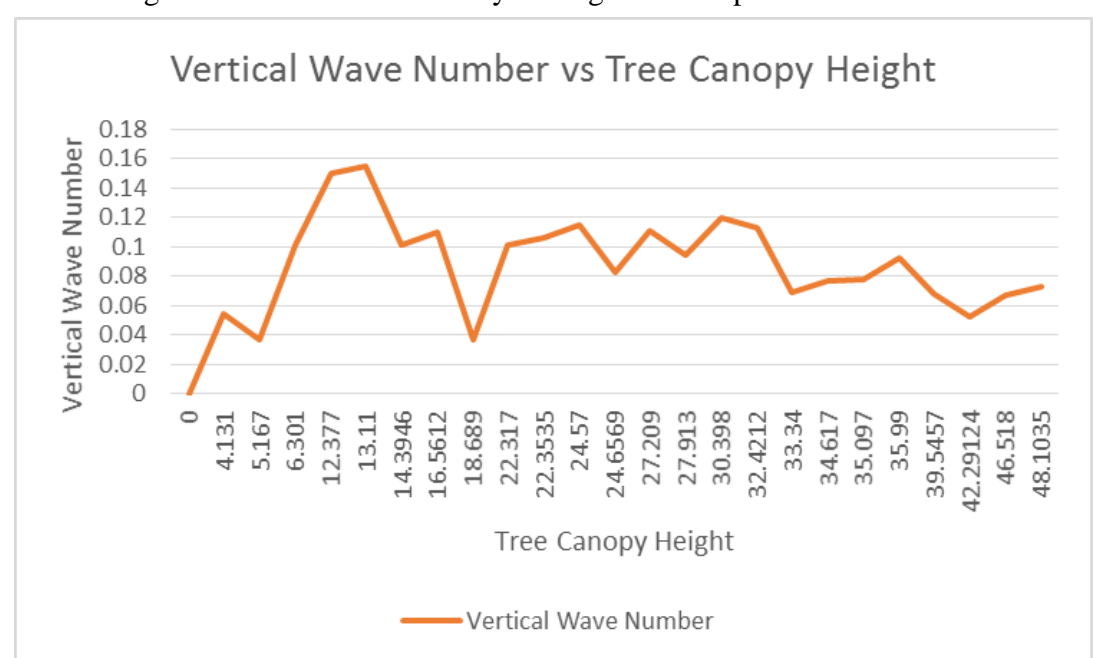

Figure 8 . Vertical wave number vs tree canopy height
The field data collected from sixteen 0.25 ha plots from the study area is used to validate the results obtained through $\mathrm{RVoG}$ inversion technique. The pixels of the tree canopy height results area averaged as per the methodology described in the previous section to match the spatial resolution of the results with the extent of the field plots on the ground. The plots are selected at distributed at locations to cover different range locations.

Figure 9 shows the graph between estimated tree height and the tree height data collected from the field. By analysing the graph it can be seen that the estimated tree height results are in good agreement with the field data. The results are having a good match in the $30 \mathrm{~m}$ to $40 \mathrm{~m}$ range and with slightly more deviation in the $10 \mathrm{~m}$ to $20 \mathrm{~m}$ range and also at $40 \mathrm{~m}$ to $50 \mathrm{~m}$ range. This can be due to the methodology described above, while the orange dot is the other alternate ground solution which was discarded.

Even though the HV coherence is close to the optimized high coherence, they are not equal. This is because the HV coherence usually contains a small amount of ground backscattering compared to most of the other polarizations, it is almost never the polarization with the absolute smallest amount of ground backscattering out of all possible polarization states. This is the reason for the requirement of coherence optimization.

Figure 7 shows the tree canopy height estimated using multibaseline RVoG inversion technique. The white colour regions

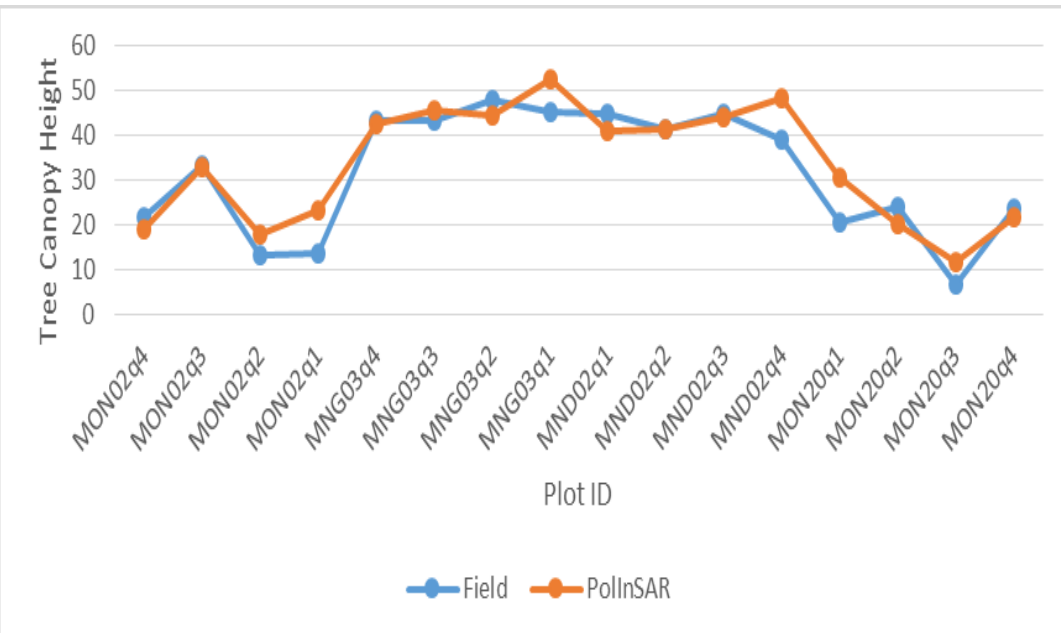
unavailability of appropriate baselines for these ranges. The overall deviation between the field data and the estimated tree canopy height is $3.75 \mathrm{~m}$.

\section{CONCLUSIONS}

Estimation of the forest canopy height is very important for the estimation of carbon stock present in forests. Remote sensing is the ideal method to estimate the forest canopy height on a global scale very accurately with limited expenses and fieldwork. The availability of Quad-Pol PolInSAR datasets with different baselines makes the multi-baseline RVoG inversion technique an ideal candidate for this purpose. The results obtained through this study shows that the tree canopy height retrieved through this technique is in a good match with the field data.

\section{ACKNOWLEDGEMENTS}

We express our sincere thanks to JPL/NASA for providing the UAVSAR datasets, field data for validation and the Kapok python library for the Multi-baseline PolInSAR processing. We are also grateful to Indian Institute of Remote Sensing, Dehradun for providing all the necessary support and infrastructure required for carrying out this study.

Figure 9. Field data vs estimated tree height 


\section{REFERENCES}

Cloude, S., Papathanassiou, K., 2001. Single-Baseline Polarimetric SAR Interferometry. IEEE Trans. Geosci. Remote 39.

Cloude, S.R., Papathanassiou, K.P., 2003. Three-stage inversion process for polarimetric SAR interferometry. IEE Proc. - Radar, Sonar Navig. 150, 125. https://doi.org/10.1049/ip-rsn:20030449

Cloude, S.R., Papathanassiou, K.P., 1998. Polarimetric SAR Interferometry. IEEE Trans. Geosci. Remote Sens. 36, 15511565. https://doi.org/10.1109/36.718859

Denbina, M., Simard, M., Hawkins, B., 2018. Forest Height Estimation Using Multibaseline PolInSAR and Sparse Lidar Data Fusion. IEEE J. Sel. Top. Appl. Earth Obs. Remote Sens. PP, 119. https://doi.org/10.1109/JSTARS.2018.2841388

Flynn, T., Tabb, M., Carande, R., 2002. Coherence Region Shape Extraction for Vegetation Parameter Estimation in Polarimetric SAR Interferometry, in: IEEE International Geoscience and Remote Sensing Symposium. pp. 2596-2598. https://doi.org/10.1109/IGARSS.2002.1026712

Joshi, S.K., Kumar, S., Agrawal, S., 2016. Performance of PolSAR backscatter and PolInSAR coherence for scattering characterization of forest vegetation using TerraSAR-X data. J. Appl. Remote Sens. 11, 987707. https://doi.org/10.1117/12.2223898

Kugler, F., Lee, S.K., Hajnsek, I., Papathanassiou, K.P., 2015. Forest Height Estimation by Means of Pol-InSAR Data Inversion: The Role of the Vertical Wavenumber. IEEE Trans. Geosci. Remote Sens. 53, 5294-5311. https://doi.org/10.1109/TGRS.2015.2420996

Kumar, S., Joshi, S.K., Govil, H., 2017a. Spaceborne PolSAR tomography for forest height retrieval. IEEE J. Sel. Top. Appl. Earth Obs. Remote Sens. 10, 5175-5185. https://doi.org/10.1109/JSTARS.2017.2741723

Kumar, S., Khati, U.G., Chandola, S., Agrawal, S., Kushwaha, S.P.S., 2017b. Polarimetric SAR Interferometry based modeling for tree height and aboveground biomass retrieval in a tropical deciduous forest. Adv. Sp. Res. 60, 571-586. https://doi.org/10.1016/j.asr.2017.04.018

Kumar, S., Sara, R., Singh, J., Agrawal, S., Kushwaha, S.P.S., 2018. Spaceborne PolInSAR and ground-based TLS data modeling for characterization of forest structural and biophysical parameters. Remote Sens. Appl. Soc. Environ. 11, 241-253. https://doi.org/10.1016/j.rsase.2018.07.010

Lee, J.-S., Pottier, E., 2009. Polarimetric Radar Imaging: From Basics to Applications, CRC Press. https://doi.org/10.1201/9781420054989.

Lee, S., Kugler, F., Papathanassiou, K., Hajnsek, I., 2011. Multibaseline polarimetric sar interferometry forest height inversion approaches. PolINSAR2011 i.

Mohd Zaki, N.A., Latif, Z.A., Suratman, M.N., 2018. Modelling above-ground live trees biomass and carbon stock estimation of tropical lowland Dipterocarp forest: integration of field-based and remotely sensed estimates. Int. J. Remote Sens. 39, 23122340. https://doi.org/10.1080/01431161.2017.1421793
Neumann, M., Ferro-Famil, L., Reigber, A., 2010. Estimation of forest structure, ground, and canopy layer characteristics from multibaseline polarimetric interferometric SAR data. IEEE Trans. Geosci. Remote Sens. 48, 1086-1104. https://doi.org/10.1109/TGRS.2009.2031101

Rosen, P.A., Hensley, S., Wheeler, K., Sadowy, G., Miller, T., Shaffer, S., Muellerschoen, R., Zebker, H., 2007. UAVSAR: New NASA Airborne SAR System for Research. IEEE A\&E Syst. Mag.

Sai Bharadwaj, P., Kumar, S., Kushwaha, S.P.S., Bijker, W., 2015. Polarimetric scattering model for estimation of above ground biomass of multilayer vegetation using ALOS-PALSAR quad-pol data. Phys. Chem. Earth 83-84, 187-195. https://doi.org/10.1016/j.pce.2015.09.003

Treuhaft, R.N., Madsen, S.N., Moghaddam, M., Zyl, J.J. Van, 1996. Vegetation characteristics and underlying topography from interferometric radar. Radio Sci. 31, 1449-1485.

Zhou, Y., Hong, W., Cao, F., 2009. An Improvement of Vegetation Height Estimation Using Multi-baseline Polarimetric Interferometric SAR Data. PIERS Online 5, 6-10. https://doi.org/10.2529/PIERS080907033305 